\title{
Familial Giant Cell Hepatitis with Low Bile Acid Concentrations and Increased Urinary Excretion of Specific Bile Alcohols: A New Inborn Error of Bile Acid Synthesis?
}

\author{
PETER T. CLAYTON, MINNE CASTEELS, GIORGINA MIELI-VERGANI, AND
}

ALEXANDER M. LAWSON

\begin{abstract}
Metabolic Disease Unit, Institute of Child Health, London WCIN 1EH, United Kingdom [P.T.C., M.C.]; Department of Child Health, King's College Hospital, London SE5L 9RS, United Kingdom [G.M.-V.]; and Section of Clinical Mass Spectrometry, Clinical Research Centre, Harrow, Middlesex HAI 3 UJ,
\end{abstract}

United Kingdom [A.M.L.]

\begin{abstract}
A 9-wk-old infant with familial giant cell hepatitis and severe intrahepatic cholestasis had low plasma concentrations of chenodeoxycholic acid and cholic acid and elevated plasma concentrations of $5 \beta$-cholestane- $3 \alpha, 7 \alpha, 12 \alpha, 25$-tetrol, $5 \beta$-cholestane$3 \alpha, 7 \alpha, 12 \alpha, 24 \xi$-tetrol, and $5 \beta$-cholcst-24-ene- $3 \alpha, 7 \alpha, 12 \alpha$-triol. Analysis of the urine by fast atom bombardment mass spectromctry and by gas chromatography-mass spectrometry after treatment with Helix pomatia glucuronidase/sulfatase showed that the major cholanoids in urine were the glucuronides of $5 \beta$ cholestane- $3 \alpha, 7 \alpha, 12 \alpha, 24 S, 25$-pentol, $5 \beta$-cholestane- $3 \alpha, 7 \alpha, 12 \alpha, 25$ tctrol, and $5 \beta$-cholcstane- $3 \alpha, 7 \alpha, 12 \alpha, 24 \xi$-tetrol. These results are consistent with an inborn error of the 25-hydroxylase pathway for bile acid synthesis, specifically one of the enzymes responsible for conversion of $5 \beta$-cholestane- $3 \alpha, 7 \alpha, 12 \alpha, 24 S, 25$-pentol to cholic acid and acctone. Treatment with chenodeoxycholic acid was tried on two occasions. On the first it appeared to precipitate a rise in bilirubin, on the second the liver function tests improved and the improvement was maintained when the
\end{abstract}

ABSTRACT
The primary bile acids, chenodeoxycholic acid and cholic acid, are synthesized from cholesterol (1). In one inborn error of metabolism affecting this pathway, $3 \beta$-hydroxy- $\Delta^{5}-\mathrm{C}_{27^{-}}$ steroid dehydrogenase deficiency, failure to synthesize the primary bile acids is associated with hepatitis, cholcstasis, steatorrhea, and fat-soluble vitamin malabsorption (2). The first cluc to defective bilc acid synthesis was the observation that, in affected paticnts, cholestasis was associated with low plasma concentrations of chenodeoxycholic acid and cholic acid; other

Received May 19, 1994; accepted November 11, 1994.

Correspondence: Dr. Peter T. Clayton, Mctabolic Disease Unit, Institute of Child Health, 30 Guilford St., London WCIN IEH, UK.

Supported by the Child Health Research Appeal Trust and the Children's Liver Disease Foundation. M.C. is "Postdoctoraal Onderzocker" of the Belgian "Nationaal Fonds voor Wetenschappelijk Onderzock." treatment was modified to a combination of chenodeoxycholic acid and cholic acid and finally, cholic acid alone. Despite the normalization of liver function tests, a liver biopsy at $1.25 \mathrm{y}$ showed an active cirrhosis. Nonetheless, the child is thriving at the age of $3.5 \mathrm{y}$, whereas an affected sibling died at 13 mo. (Pediatr Res 37: 424-431, 1995)

\author{
Abbreviations \\ CTX, cerebrotendinous xanthomatosis \\ TMS, trimethylsilyl \\ GC, gas chromatography \\ MS, mass spectrometry \\ FAB, fast atom bombardment \\ AST, aspartate aminotransferase \\ ALP, alkaline phosphatase \\ LFT, liver function test \\ $\mathbf{m} / \mathbf{z}$, mass $/$ charge ratio
}

patients with cholestasis have high plasma concentrations (3). The site of the defect was determined by identifying the unusual metabolites in the urine followed by appropriate enzymology (4). Treatment with chenodeoxycholic acid led to a dramatic improvement providing support for the hypothesis that deficiency of primary bile acids was an important factor in the cholestasis and malabsorption $(2,5-7)$. Other inborn errors of bile acid synthesis have been described (2). CTX leads to the excretion of large amounts of bile alcohol glucuronides in the urine (8). Patients with CTX do not suffer from neonatal cholestasis perhaps because, although the 27-hydroxylase pathway for side chain oxidation is blocked, some cholic acid can be synthesized by the alternative 25-hydroxylation pathway for side chain oxidation $(8-10)$ (see Fig. 1). [In this report the 25 -pro- $R$ methyl group of cholesterol has been designated $\mathrm{C} 26$ 

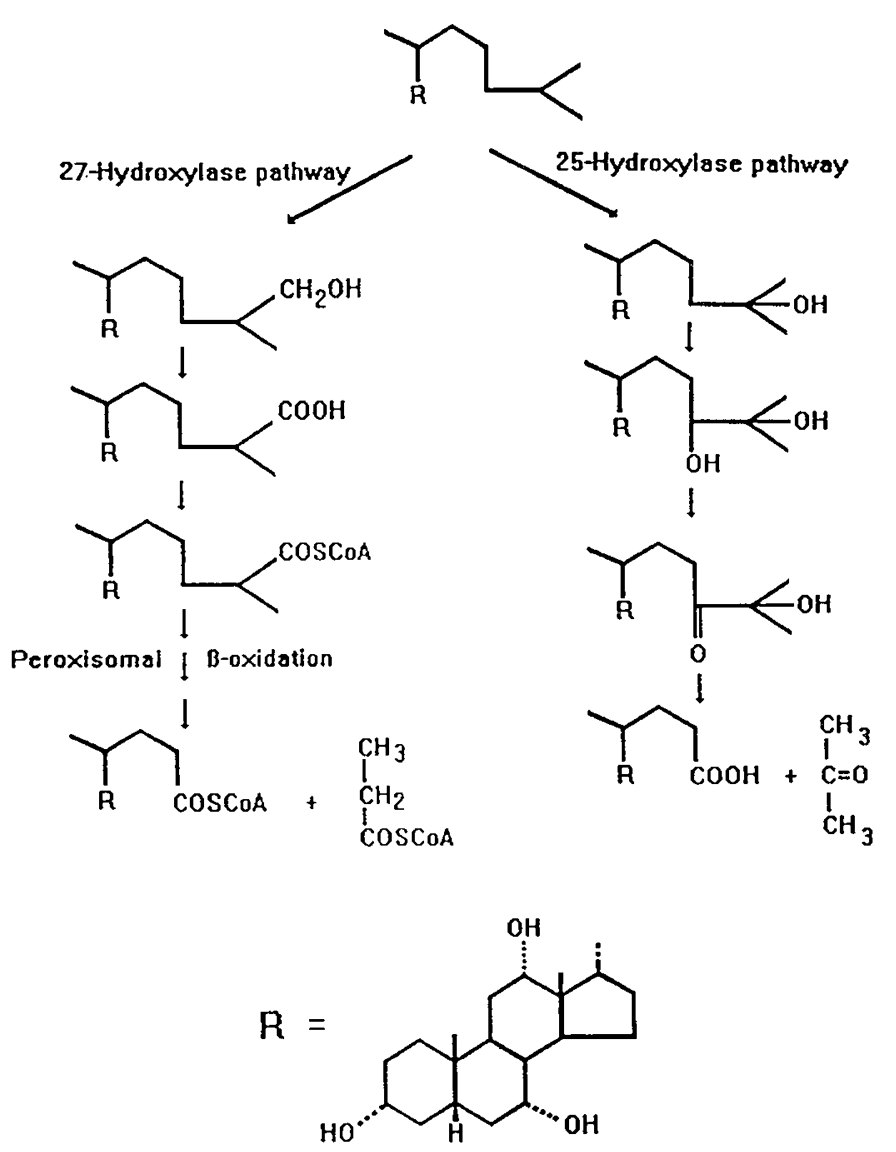

Figure 1. Pathways for conversion of $5 \beta$-cholestane- $3 \alpha, 7 \alpha, 12 \alpha$-triol to cholic acid. On the left is the 27-hydroxylase pathway, which includes $\beta$-oxidation in the peroxisomes; on the right is the 25 -hydroxylase pathway.

and the 25-pro-S methyl group C27. Using this convention the mitochondrial $\omega$-hydroxylase involved in bile acid synthesis is a 27-hydroxylase (9).]

This study describes an additional infant with familial cholestasis and low plasma concentrations of chenodeoxycholic acid and cholic acid. Analysis of the cholanoids (bile acids and alcohols) in the urine revealed that he was excreting large amounts of the glucuronides of $5 \beta$-cholestane- $3 \alpha, 7 \alpha, 12 \alpha, 24 S, 25$ pentol, $5 \beta$-cholestane- $3 \alpha, 7 \alpha, 12 \alpha, 25$-tetrol, and $5 \beta$-cholestane$3 \alpha, 7 \alpha, 12 \alpha, 24 \xi$-tetrol. These findings are compatible with an inborn error affecting conversion of $5 \beta$-cholestane- $3 \alpha, 7 \alpha, 12 \alpha$ triol to cholic acid via $5 \beta$-cholestane- $3 \alpha, 7 \alpha, 12 \alpha, 25$-tetrol and $5 \beta$-cholestane- $3 \alpha, 7 \alpha, 12 \alpha, 24 S, 25$-pentol-the 25 -hydroxylase pathway of side chain oxidation described by Shefer et al. (10). Specifically, it suggests a defect in the conversion of $5 \beta$ cholestane- $3 \alpha, 7 \alpha, 12 \alpha, 24 S, 25$-pentol to cholic acid and acetone.

\section{METHODS}

\section{Materials}

Materials used for analysis of plasma bile acids by GC-MS (11-14) and for analysis of urinary cholanoids by FAB-MS (3, 14,15 ) have been described previously. For analysis of urinary bile alcohols by GC-MS, $\beta$-glucuronidase/sulfatase from Helix pomatia was obtained from Sigma Chemical Co. Ltd. (Poole, Dorset, UK).
Reference compounds. $5 \beta$-Cholestane- $3 \alpha, 7 \alpha, 12 \alpha$-triol was a gift from Dr. I Björkhem (Karolinska Institute, Huddinge, Sweden). $5 \beta$-Cholestane- $3 \alpha, 7 \alpha, 12 \alpha, 25$-tetrol and $5 \beta$ cholestane- $3 \alpha, 7 \alpha, 12 \alpha, 25 \xi, 26$-pentol were from the Medical Research Council steroid reference collection. $5 \beta$-Cholestane$3 \alpha, 7 \alpha, 12 \alpha, 24 \xi$-tetrol, $5 \beta$-cholestane- $3 \alpha, 7 \alpha, 12 \alpha, 24 R, 25$-pentol, and $5 \beta$-cholestane- $3 \alpha, 7 \alpha, 12 \alpha, 24 S, 25$-pentol were kindly provided by Prof. J. Sjövall (Karolinska Institute, Stockholm, Sweden). An additional sample of the $24 S$ pentol was generously donated by Prof. G. Salen and Dr. B. Dayal (University of Medicine and Dentistry, Newark, NJ). (25R)- $5 \beta$-Cholestan$3 \alpha, 7 \alpha, 12 \alpha, 27$-tetrol was synthesized by reduction of methyl (25R)-3 $\alpha, 7 \alpha, 12 \alpha$-trihydroxy- $5 \beta$-cholestanoate using $\mathrm{LiAlH}_{4}$ in diethyl ether. 5-Cholestene-3 $\beta, 7 \alpha$-diol ( $7 \alpha$-hydroxycholesterol), 5-cholestene-3 $\beta, 7 \beta$-diol (7 $\beta$-hydroxycholesterol), $3 \alpha, 12 \alpha$-dihydroxy-24-nor-5 $\beta$-cholan-23-oic acid (nordeoxycholic acid), and methyl $3 \alpha, 12 \alpha$-dihydroxy-5 $\beta$ cholanoate (methyl deoxycholate) were from Steraloids Inc. (Wilton, NH). TMS ethers for GC-MS analysis were prepared by heating $\left(60^{\circ} \mathrm{C}, 1 \mathrm{~h}\right)$ in TriSil (Pierce, Rockford, IL). Samples were injected in reagent. Retention indices of reference compounds are in Table 1. Mass spectra have been documented (16-21).

\section{Analyses}

Plasma cholanoid analysis. Plasma bile acids were analyzed by GC-MS using previously described methods (11-14) with minor modifications. Nor-deoxycholic acid was used as internal standard instead of $3 \alpha$-hydroxy-7-oxo- $5 \beta$-cholanoic acid, and toluene was used in place of benzene in the alumina chromatography stage of the assay. Analysis of quality control samples showed that these changes had no effect on quantitation of plasma bile acids. Reference ranges for plasma bile acid concentrations in normal and cholestatic infants have been documented previously $(3,12)$.

Analysis of cholanoids in urine. Urine was analyzed by FAB-MS after extraction on octadecylsilane-bonded silica cartridges $(3,15)$. The urine was then further analyzed by GC-MS after hydrolysis of bile alcohol sulfates and glucuronides with

Table 1. Retention indices of trimethylsilyl ethers of reference compounds

\begin{tabular}{|c|c|}
\hline Reference compound & $\begin{array}{l}\text { Retention } \\
\text { index }\end{array}$ \\
\hline $\begin{array}{l}\text { Methyl } 3 \alpha, 12 \alpha \text {-dihydroxy-24-nor-5 } \beta \text {-cholan-23-oate } \\
\text { (methyl ester of nordeoxycholic acid*) }\end{array}$ & 3070 \\
\hline 5-Cholestene-3 $\beta, 7 \alpha$-diol (7 $\alpha$-hydroxycholesterol) & 3150 \\
\hline $5 \beta$-Cholestane- $3 \alpha, 7 \alpha, 12 \alpha$-triol & 3160 \\
\hline $\begin{array}{l}\text { Methyl } 3 \alpha, 12 \alpha \text {-dihydroxy } 5 \beta \text {-cholanoate (methyl } \\
\quad \text { deoxycholate } \dagger \text { ) }\end{array}$ & 3190 \\
\hline 5-Cholestene-3 $\beta, 7 \beta$-diol ( $7 \beta$-hydroxycholesterol) & 3250 \\
\hline $5 \beta$-Cholestane- $3 \alpha, 7 \alpha, 12 \alpha, 24 \xi$-tetrol & 3365 \\
\hline $5 \beta$-Cholestane- $3 \alpha, 7 \alpha, 12 \alpha, 25$-tetrol & 3413 \\
\hline 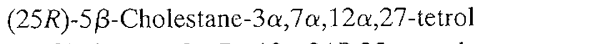 & 3453 \\
\hline $5 \beta$-Cholestane- $3 \alpha, 7 \alpha, 12 \alpha, 24 R, 25$-pentol & 3570 \\
\hline $5 \beta$-Cholestane- $3 \alpha, 7 \alpha, 12 \alpha, 24 S, 25$-pentol & 3585 \\
\hline $5 \beta$-Cholestane- $3 \alpha, 7 \alpha, 12 \alpha, 25 \xi, 26$-pentol & 3625 \\
\hline
\end{tabular}

* Internal standard in analyses of plasma.

$\dagger$ Internal standard in analyses of urine bile alcohols. 
H. pomatia juice using a method similar to that of Wolthers et al. (22). After determination of the urinary creatinine concentration, the cholanoids from $2 \mathrm{~mL}$ of urine were extracted on a C18 cartridge and then reconstituted in $2 \mathrm{~mL}$ of water. After the addition of $100 \mu \mathrm{L}$ of $5 \mathrm{M}$ sodium acetate buffer, $\mathrm{pH} 4.7$, and $30 \mu \mathrm{L}$ of glucuronidase/sulfatase, the samples were incubated for $20 \mathrm{~h}$ at $37^{\circ} \mathrm{C}$. For quantitative analyses, $50 \mu \mathrm{L}$ of 250 $\mu \mathrm{M}$ methyl deoxycholate was added after the incubation. The cholanoids were then extracted with a C18 cartridge, eluting with $2 \times 5 \mathrm{~mL}$ of methanol. The dried eluate was reconstituted in toluene/hexanc $(1: 1, \mathrm{vol} / \mathrm{vol})$ and subjected to chromatography on neutral alumina (as used in the purification of bile acid methyl esters). The TMS ethers of the bile alcohols were prepared and analyzed by GC-MS using the same gas chromatography and mass spectrometry settings as used for bile acids $(13,14)$. Urinary bile alcohol profiles from the patient described below were compared with profiles from normal infants, from infants with cholestatic liver disease of known causc and from three adults with CTX (samples supplied by Dr. B. J. Koopman). Quantitation of urinary bile alcohol concentrations was achieved by comparing peak areas with the area of the internal standard peak.

Analysis of duodenal bile. Duodenal juice was aspirated before and after i.v. injection of cholecystokinin. The bile was analyzed by FAB-MS and by GC-MS after enzymatic deconjugation (14). Quantitation of bile acid concentrations was achieved by the use of nordeoxycholic acid as internal standard (as for plasma samples).

\section{Case History}

The propositus, AA, was the fourth child of healthy unrelated Asian parents. Their first child died at 13 mo, having been jaundiced all his life; their second is a boy who is well; and their third was a still birth. AA was born at term by vaginal delivery. Jaundice was noted at $7 \mathrm{~d}$, and examination revealed hepatomegaly. He was referred for investigation at $9 \mathrm{wk}$ when examination revealed the following: weight, $5.85 \mathrm{~kg}$ (90th percentile); head circumference, $40 \mathrm{~cm}$ (90th percentile); deep jaundice; and firm liver edge $4 \mathrm{~cm}$ from the costal margin in the midclavicular line.

Investigations revealed hemoglobin $10.7 \mathrm{~g} / \mathrm{dL}$; reticulocytes $3.2 \%$; film, some crenated cells; prothrombin ratio 1.2; bilirubin $179 \mu \mathrm{M}$ (conjugated $143 \mu \mathrm{M}$ ); AST $575 \mathrm{IU} / \mathrm{L}$ (normal 10-50 IU/L); $\gamma$-glutamyl-transpeptidase $38 \mathrm{IU} / \mathrm{L}$ (normal 5-55 IU/L); ALP $1590 \mathrm{IU} / \mathrm{L}$ (normal 30-380 IU/L); albumin $38 \mathrm{~g} / \mathrm{L}$; creatinine, urea, electrolytes, calcium, and phosphate normal; cholesterol $6.3 \mathrm{mM}$ (normal $1.7-4.4 \mathrm{mM}$ ); triglycerides 1.7 $\mathrm{mM}$ (normal $0.6-1.9 \mathrm{mM}$ ); plasma amino acids normal; $\alpha_{1^{-}}$ antitrypsin phenotype PiMM; galactose-1-phosphate uridyl transfcrase normal; cortisol, thyroid-stimulating hormone, and L-thyroxine normal; and bone marrow aspirate, no storage cells. There was no evidence of urinary tract infection, and serologic tests for hepatitis A and B were also negative.

An ultrasound examination showed normal liver parenchyma but a very small gallbladder. The right hepatic and common bile ducts were visualized and were not dilated. The portal vein was patent and the spleen measured $7.2 \mathrm{~cm}$. A methyl bromida scan showed no definite evidence of biliary excretion into the bowel. A percutaneous liver biopsy showed a nonspecific hepatitis with giant cells and a few areas of focal bridging necrosis. There was a marked inflammatory cell infiltrate and very marked cholestasis. In view of the severe hepatitis and cholestasis, AA was treated with prednisolone, 10 $\mathrm{mg}$ daily (at the age of $0.2 \mathrm{y}$ ). Despite this treatment he failed to thrive on breast milk, and supplementation with Pregestemil (Mead Johnson, Hoonslow, UK) was advised. Over the next $0.17 \mathrm{y}$, there was a fall followed by a small rise in serum bilirubin and a small rise in the AST (Fig. 2). At $0.37 \mathrm{y}$, treatment with chenodeoxycholic acid $(10 \mathrm{mg} / \mathrm{kg} / \mathrm{d})$ was commenced, but over the next $2 \frac{1}{2} \mathrm{wk}$ the bilirubin doubled as did the ALP and, although there was no rise in AST, chenodeoxycholic acid treatment was discontinued at $0.42 \mathrm{y}$. Over the next $2 \mathrm{wk}$, the bilirubin continued to rise (to $350 \mu \mathrm{M}$ ), and there was also a marked rise in AST (to $2530 \mathrm{IU} / \mathrm{L}$ ). Massive firm hepatomegaly $(10 \mathrm{~cm}$ from the costal margin) was noted. Chenodeoxycholic acid $(10 \mathrm{mg} / \mathrm{kg})$ was recommenced at 0.47 $\mathrm{y}$, and the bilirubin fell to $260 \mu \mathrm{M}$, the AST to $690 \mathrm{IU} / \mathrm{L}$. At this time $(0.48 \mathrm{y})$, pruritus, which had been apparent from 0.3 $\mathrm{y}$, became severe, and treatment with phenobarbitone $(2 \mathrm{mg} /$ $\mathrm{kg}$ ) was commenced. At 0.49 y the bile acid therapy was changed to chenodeoxycholic acid $(5 \mathrm{mg} / \mathrm{kg} / \mathrm{d})$ plus cholic acid $(5 \mathrm{mg} / \mathrm{kg} / \mathrm{d})$. From this point on there was a steady improvement in bilirubin and AST (Fig. 2). A second liver biopsy performed at $0.52 \mathrm{y}$ confirmed that the deterioration in liver function tests which had been observed between 0.2 and 0.52
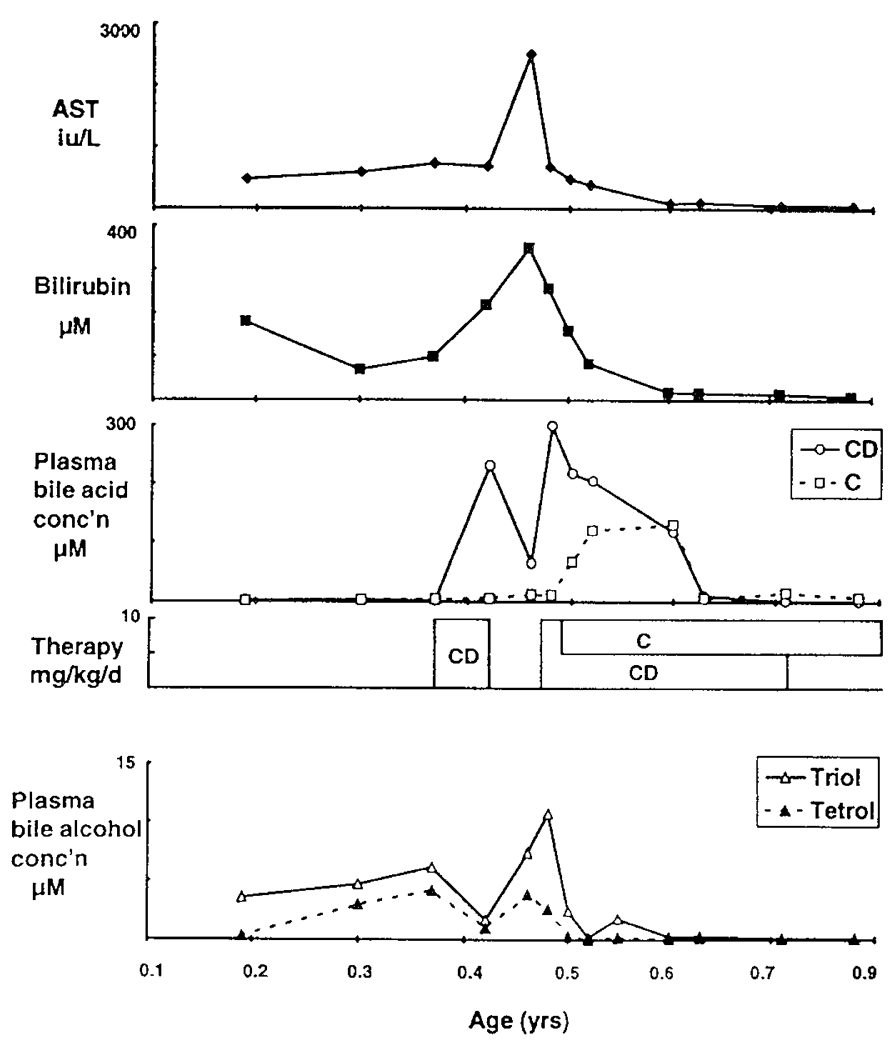

Figure 2. Patient AA's LFT and plasma cholanoid concentrations between 0.2 and $0.7 \mathrm{y}$. Effect of treatment with chenodeoxycholic acid $(C D)$ and cholic acid $(C)$. Triol, $5 \beta$-cholest-24-ene-3 $\alpha, 7 \alpha, 12 \alpha$-triol; Tetrol, $5 \beta$-cholestane$3 \alpha, 7 \alpha, 12 \alpha, 25$-tctrol. 
y had been accompanied by a deterioration in liver histology; there was an established cirrhosis with cholestasis and active (although reduced) portal inflammation.

Pruritus remained a problem, and rifampicin $(10 \mathrm{mg} / \mathrm{kg} / \mathrm{d})$ was added to the treatment regimen at $0.52 \mathrm{y}$. By $0.6 \mathrm{y}$ the bilirubin was normal $(18 \mu \mathrm{M})$ and the AST only mildly elevated (91 IU/L). At $0.71 \mathrm{y}$, chenodeoxycholic acid therapy was discontinued but cholic acid continued at a dose of 5 $\mathrm{mg} / \mathrm{kg} / \mathrm{d}$. The improvement in LFT was maintained when cholic acid, rifampicin, and phenobarbitone were the only drugs in use, and by $0.78 \mathrm{y}$ the bilirubin was normal $(8 \mu \mathrm{M})$ as was the AST (49 IU/L). The liver was much smaller than at $0.47 \mathrm{y}$ (the edge being palpable $3 \mathrm{~cm}$ from the costal margin); the spleen was palpable $1.5 \mathrm{~cm}$ from the left costal margin. Pruritus was also considerably better, and weight gain was normal.

When AA was 1.15 y old, a slight rise in bilirubin, AST, and ALP were noted. The dose of cholic acid was increased from 40 to $80 \mathrm{mg} / \mathrm{d}(8 \mathrm{mg} / \mathrm{kg} / \mathrm{d})$, and the LFT improved again. Despite the normal LFT, a liver biopsy at 1.25 y was markedly abnormal. Portal fibrosis was seen, associated with edema and a cellular infiltrate. There was localized hepatocellular necrosis, giant cell transformation, and cellular infiltration of the parenchyma. There was evidence of cholestasis (bile pigment in canaliculi). The architecture was disrupted to the point of cirrhosis, there was disruption of the limiting plates, and there was bile duct reduplication. Thus the biopsy suggested an active cirrhosis.

Between 1.25 and 3.5 y, AA was treated with cholic acid, 80 $\mathrm{mg}$ daily, only (the rifampicin and phenobarbitone having been discontinued). He continued to show normal growth and examination showed no hepatosplenomegaly or stigmata of chronic liver disease. All LFT were normal.

\section{RESULTS}

\section{Pretreatment Samples}

Plasma cholanoid analysis. The chromatogram obtained from a plasma sample from $\mathrm{AA}$ is shown in Fig. 3 (upper trace). Chenodeoxycholic acid and cholic acid were both detectable (peaks 7 and 8), but their concentrations were much lower than in other infants and children with cholestatic liver disease (Table 2). The chromatogram also revealed the presence of four compounds that we have never previously detected in the plasma of children with or without liver diseasepeaks 4, 6, 10, and 11 in Figure 3. Peak 11 was readily identified by comparison with the reference compound as $5 \beta$-cholestane- $3 \alpha, 7 \alpha, 12 \alpha, 25$-tetrol. The presence of this compound and the low plasma concentrations of chenodeoxycholic acid and cholic acid were reminiscent of the chromatogram from a 55-y-old lady with CTX (Fig. 3, lower trace). However, there were other compounds present in the plasma of AA that were not seen in the patient with CTX. Peak 6 produced a mass spectrum identical with the TMS ether of $5 \beta$-cholest-24-ene$3 \alpha, 7 \alpha, 12 \alpha$-triol (17). Peak 4 was an isomer of peak 6 but the mass spectrum had additional major fragment ions of $\mathrm{m} / \mathrm{z} 281$ and 371 , suggesting a $\Delta^{23}$ structure in the side chain; this compound was therefore provisionally identified as $5 \beta$-cholest-

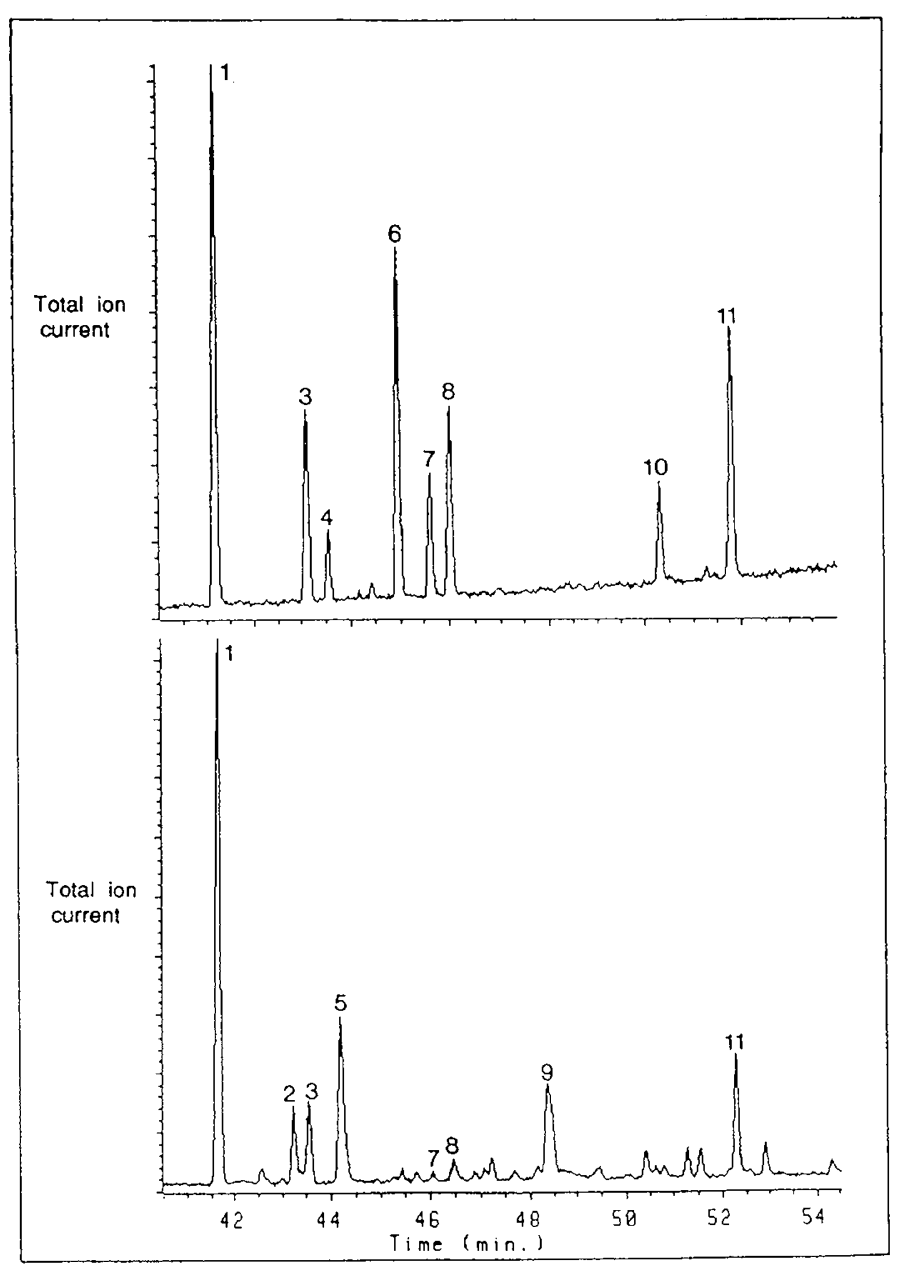

Figure 3. Total ion currents obtained on GC-MS analysis of plasma from patient AA (upper trace) and from a patient with CTX (lower trace). Mass spectra and retention indices permitted identification of peaks as follows: $I$, nordeoxycholic acid (internal standard); 2, cholestane-3,7,12-triol; 3, cholesterol ( + some $7 \alpha$-hydroxycholesterol in CTX sample); 4 , side chain unsaturated cholestenetriol (?5 $\beta$-cholest-23-ene- $3 \alpha, 7 \alpha, 12 \alpha$-triol); 5, 5 $\beta$-cholestanc$3 \alpha, 7 \alpha, 12 \alpha$-triol; $6, ? 5 \beta$-cholest-24-ene- $3 \alpha, 7 \alpha, 12 \alpha$-triol; 7 , chenodeoxycholic

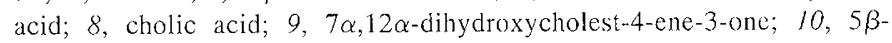
cholestane- $3 \alpha, 7 \alpha, 12 \alpha, 24 \xi$-tetrol; $11,5 \beta$-cholestane- $3 \alpha, 7 \alpha, 12 \alpha, 25$-tetrol.

Table 2. Plasma concentrations of chenodeoxycholic acid and cholic acid in the plasma of AA, the plasma of normal infants and the plasma of infants with cholestatic liver disease

\begin{tabular}{|c|c|c|c|}
\hline \multirow[b]{2}{*}{ Bilc acid } & \multicolumn{3}{|c|}{ Plasma concentration $(\mu \mathrm{M})$} \\
\hline & $\mathrm{AA}$ & $\begin{array}{l}\text { Normal } \\
\text { infants }\end{array}$ & $\begin{array}{c}\text { Cholestatic } \\
\text { infants }\end{array}$ \\
\hline Chenodeoxycholic & $\begin{array}{l}2.2,2.0 \\
2.8,2.2\end{array}$ & $3.23-5.32$ & $25-359$ \\
\hline Cholic & $\begin{array}{l}0.62,2.8 \\
2.5,3.9\end{array}$ & $0.15-3.50$ & $7--317$ \\
\hline
\end{tabular}

23-ene-3 $\alpha, 7 \alpha, 12 \alpha$-triol. This compound was not present in the CTX plasma; peak 5 in the CTX sample, which had a similar retention time, was identified by comparison with the reference compound as $5 \beta$-cholestane- $3 \alpha, 7 \alpha, 12 \alpha$-triol. Peak 10 in the sample from AA was identified by comparison with the reference compound as $5 \beta$-cholestane- $3 \alpha, 7 \alpha, 12 \alpha, 24 \xi$-tetrol. 

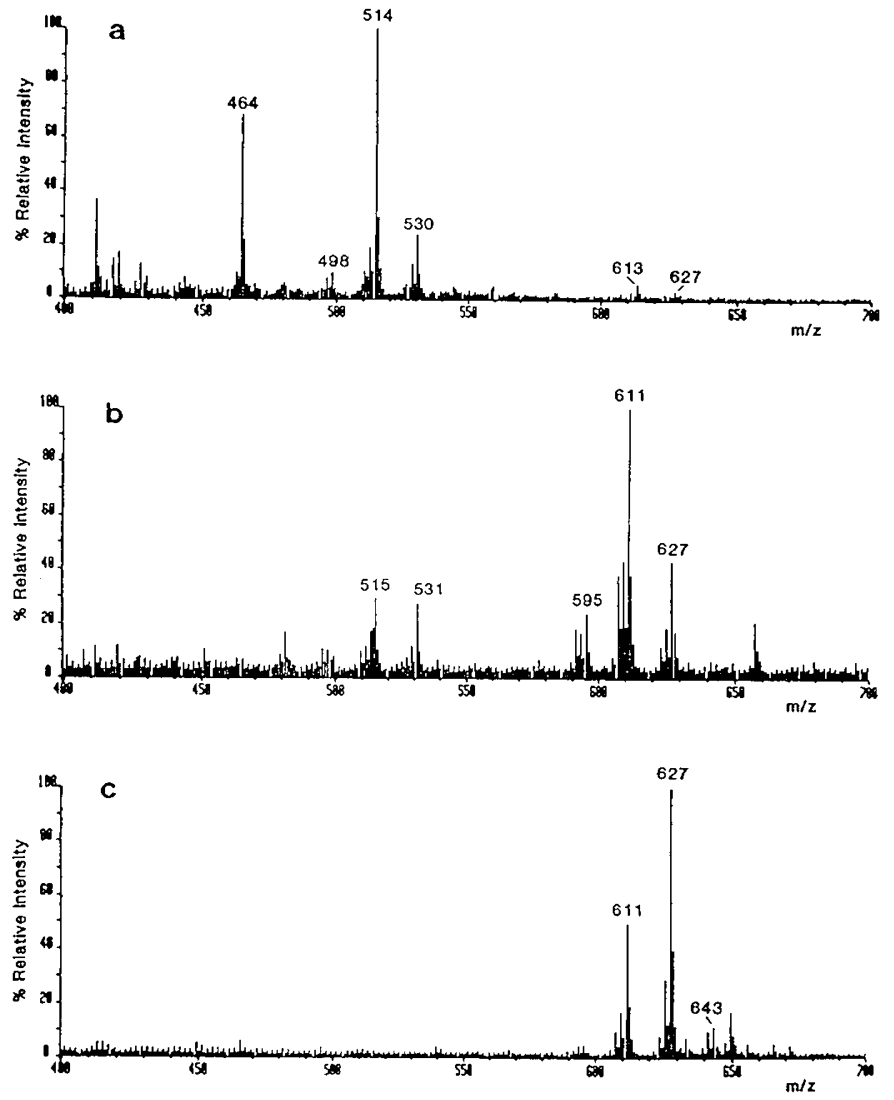

Figure 4. FAB mass spectra of urinary cholanoids from patient $\mathrm{AA}(b)$, an infant of the same age with cholestatic liver disease duc to cytomegalovirus hepatitis $(a)$, and an adult with cerebrotendinous xanthomatosis (c). Postulated origins of ions are as follows: 464, glycotrihydroxycholanoates; 498, taurodihydroxycholanoates; 514 , taurotrihydroxycholanoates; 530 , taurotetrahydroxycholanoates; 613, 27-nor-cholestanepentol glucuronides; 627 , cholestanepentol glucuronides; 515, cholestanctetrol sulfates; 531, cholestanepentol sulfates; 595, cholestanctriol glucuronides, 611, cholestanetetrol glucuronides; and 643, cholestanehexol glucuronides.

Analysis of urinary cholanoids. The negative ion FAB mass spectrum of urine from AA is shown in Figure $4 b$, alongside the FAB mass spectrum of urine from an infant with cholestatic liver disease due to cytomegalovirus hepatitis (Fig. $4 a$ ) and the FAB mass spectrum of the urine from a patient with CTX (Fig. $4 c$ ). The postulated origins of the major ions are indicated in the figure lcgend; these are in part based on the results of the GC-MS analysis (given below). The largest peak in the spectrum from the urine of AA (Fig. $4 b$ ) had a mass/charge ratio of 611 -compatible with the quasimolecular $(\mathrm{M}-\mathrm{H})^{-}$ions of cholestanetetrol glucuronides. The second largest peak was of $\mathrm{m} / \mathrm{z} 627$, suggestive of cholestanepentol glucuronides. The presence of large amounts of bilc alcohol glucuronides in the urine with undetectable bile acid excretion was similar to the pattern scen in the urine of an adult with CTX (Fig. 4c). By contrast, 60 infants with severe cholestatic liver disease showed a pattern similar to that seen in Figure $4 a$; the bile acid excretion was much greater than the bile alcohol excretion and the major bile alcohol was usually 27 -nor-5 $\beta$-cholestanepentol glucuronide $(\mathrm{m} / \mathrm{z}$ 613). Analysis of urine from 90 normal infants by FAB-MS revealed only small amounts of bile acids and of bile alcohol glucuronides (close to the limit of detection

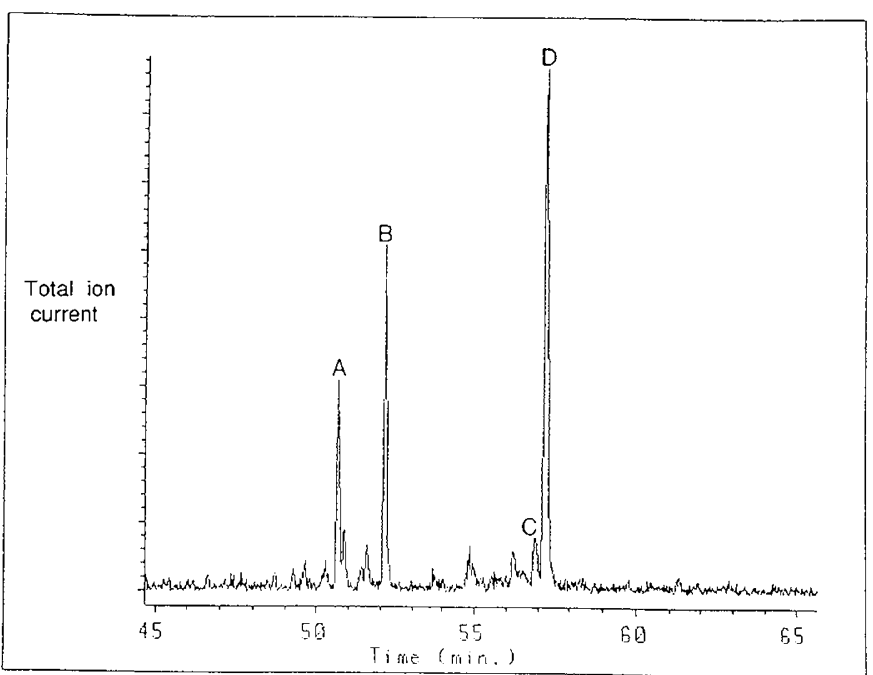

Figure 5. Results of analysis of urine from AA by GC-MS after treatment with glucuronidase/sulfatase. Mass spectra and retention indices indicated the following peak identities: $A, 5 \beta$-cholestane- $3 \alpha, 7 \alpha, 12 \alpha, 24 \xi$-tetrol; $B, 5 \beta$ cholestane- $3 \alpha, 7 \alpha, 12 \alpha, 25$-tetrol; $C$, $5 \beta$-cholestane- $3 \alpha, 7 \alpha, 12 \alpha, 24 R, 25$-pentol; $D, 5 \beta$-cholestane- $3 \alpha, 7 \alpha, 12 \alpha, 24 S, 25$-pentol.

of the method); the peak heights produced by the bile acids and bile alcohols were similar.

Analysis of the urine from AA by GC-MS after digestion with glucuronidase/sulfatase (Fig. 5) revealed that the major bile alcohol present was $5 \beta$-cholestane- $3 \alpha, 7 \alpha, 12 \alpha, 24 S, 25$ pentol (peak D); excretion of this compound was 10 times that of the $24 R$ isomer (peak C). In samples from three patients with CTX, urinary excretion of the $3 \alpha, 7 \alpha, 12 \alpha, 24$ S, 25-pentol was only twice that of the $24 R$ isomer, and, in any case, excretion of the $3 \alpha, 7 \alpha, 12 \alpha, 24,25$-pentols was appreciably less than that of other $5 \beta$-cholestane-pentols, in particular 3,7,12,22,25pentols and 3,7,12,23,25-pentols. $5 \beta$-Cholestane- $3 \alpha, 7 \alpha, 12 \alpha, 25$ tetrol was a major component of the urinary bile alcohol profile of both AA (Fig. 5, peak B) and the CTX patients. $5 \beta$ Cholestane- $3 \alpha, 7 \alpha, 12 \alpha, 24 \xi$-tetrol (Fig. 5, peak A) was a major component in AA but not in the CTX patients. Table 3 shows the results of quantitation of urinary excretion of bile alcohols in $\mathrm{AA}$, in normal infants and in infants with cholestasis. The excretions of $5 \beta$-cholestane- $3 \alpha, 7 \alpha, 12 \alpha, 24 \xi$-tetrol, $-3 \alpha, 7 \alpha, 12 \alpha$, 25 -tetrol, and $-3 \alpha, 7 \alpha, 12 \alpha, 24 S, 25$-pentol were orders of magnitude greater than in both normal and cholestatic controls. The excretion of 27 -nor- $5 \beta$-cholestane- $3 \alpha, 7 \alpha, 12 \alpha, 24,25$-pentol was not increased.

Table 3. Excretion of urinary bile alcohols by AA, by normal infants, and by infants with cholestatic liver disease

\begin{tabular}{|c|c|c|c|}
\hline \multirow[b]{2}{*}{ Bile alcohol* } & \multicolumn{3}{|c|}{$\begin{array}{l}\text { Urinary excretion in } \\
\mu \text { mols/mmol creatinine }\end{array}$} \\
\hline & AA & $\begin{array}{c}\text { Normal } \\
\text { infants } \\
(n=11)\end{array}$ & $\begin{array}{c}\text { Cholestatic } \\
\text { infants } \\
(n=6)\end{array}$ \\
\hline $5 \beta-\mathrm{C}-3 \alpha, 7 \alpha, 12 \alpha, 24 S, 25$-Pentol & 110 & $0-0.16$ & $0-0.31$ \\
\hline $5 \beta-\mathrm{C}-3 \alpha, 7 \alpha, 12 \alpha, 25-$ Tetrol & 117 & 0 & $0-0.13$ \\
\hline $5 \beta-\mathrm{C}-3 \alpha, 7 \alpha, 12 \alpha, 24 \xi$-Tetrol & 53 & 0 & 0 \\
\hline 27 -Nor-5 $\beta$-C- $3 \alpha, 7 \alpha, 24,25$-Pentol & 0 & $0-0.39$ & $0-0.20$ \\
\hline
\end{tabular}

$* 5 \beta-C=5 \beta$-cholestane 
Analysis of duodenal bile. Concentrations of bile acids in AA's duodenal juice after i.v. injection of cholecystokinin were reduced 1000-fold: chenodeoxycholic acid $0.29 \mu \mathrm{M}$ (controls 0.3-6.1 mM); cholic acid $1.12 \mu \mathrm{M}$ (controls 2.1-12.7 $\mathrm{mM}$ ). The pre-cholecystokinin concentrations were similarly reduced. The chromatogram from AA showed some other unusual features. There was a sizeable peak with the retention time of cholesterol (as was the case with chromatograms from other bile samples), but mass spectrometry indicated that, in the case of AA, this peak contained a substantial amount of $7 \alpha$-hydroxycholesterol (unlike the control samples). The chromatogram from AA also showed a peak due to $7 \beta-$ hydroxycholesterol (not detected in controls) and a series of small peaks whose spectra suggested that they were side chain unsaturated bile alcohols that were not fully identified.

\section{Follow-up Samples}

Plasma cholanoid profile. Treatment with chenodeoxycholic acid, $10 \mathrm{mg} / \mathrm{kg} / \mathrm{d}$, when AA was aged 0.37 y was associated with a dramatic rise in plasma chenodeoxycholic acid concentration with no sign of improvement in the cholestasis (Fig. 2). The plasma concentration of chenodeoxycholic acid and that of cholic acid were directly related to what was being given orally until AA was $0.55 \mathrm{y}$ when, with no change in the bile acid therapy, plasma bile acid concentrations fell dramatically; this fall coincided with a drop in the AST and bilirubin, indicating an improvement in the cholestatic liver disease. While AA was being treated with cholic acid alone subsequently, the plasma chenodeoxycholic acid concentration was subnormal $(1.2,0.5 \mu \mathrm{M})$ and the cholic acid only slightly elevated $(15,7.1 \mu \mathrm{M})$. The effect of bile acid therapy on plasma bile alcohol concentrations is shown in Figure 2 (bottom graph). The improvement in LFT was associated with a fall in the plasma concentrations of both $5 \beta$-cholestane$3 \alpha, 7 \alpha, 12 \alpha, 25$-tetrol and $5 \beta$-cholest-24-en- $3 \alpha, 7 \alpha, 12 \alpha$-triol. The urinary excretion of bile alcohol glucuronides also fell (data not shown).

\section{DISCUSSION}

The infant described in this report had low concentrations of bile acids in his duodenal bile, and despite his cholestasis he also had low concentrations in plasma and urine. This suggested a major defect in bile acid synthesis. The excretion in the urine of large amounts of bile alcohols containing the cholic acid nucleus but an 8-carbon side chain indicated that the defect affected a reaction in the conversion of the cholesterol side chain to the bile acid side chain.

Our current view of cholesterol side chain oxidation is that two alternative pathways exist (9). The first involves hydroxylation in the $\mathrm{C}-27$ position (which occurs in the mitochondria), further oxidation to a $\mathrm{C}_{27}$ bile acid, and then $\beta$-oxidation in the peroxisomes. The second pathway starts with $\mathrm{C}-25$ hydroxylation of $5 \beta$-cholestane- $3 \alpha, 7 \alpha, 12 \alpha$-triol (which occurs in the microsomes) and continues with a second hydroxylation that produces $5 \beta$-cholestane- $3 \alpha, 7 \alpha, 12 \alpha, 24(S) 25$-pentol. The $24(S)$ pentol is cleaved to produce cholic acid and acetone; a 24ketone may be an intermediate in this pathway (10) (Fig. 1).
The major cholanoid in the urine of our patient was $5 \beta$ cholestane-3 $\alpha, 7 \alpha, 12 \alpha, 24(S), 25$-pentol. Therefore the most likely site of the defect was in the cleavage of this pentol. Proof that this was indeed the defect is unfortunately lacking; we were unsuccessful in our attempts to scale down the assays described by Shefer et al. (10) so that they could be used on a few milligrams of liver biopsy. Without proof of the exact site of the defect from enzymology/DNA analysis, we have to consider other possibilities. We know from studies of CTX that a defect in an early step in the C-27 hydroxylase pathway can lead to diversion of $5 \beta$-cholestane- $3 \alpha, 7 \alpha, 12 \alpha$-triol into the C-25 hydroxylase pathway with the result that the major urinary cholanoids are pentols with hydroxyl groups in the $3 \alpha-$, $7 \alpha-, 12 \alpha$-, and C-25 positions. Presumably the 25 -hydroxylase enzyme can cope with the increased flux but subsequent steps in the pathway to cholic acid are overloaded; hence, the $5 \beta$-cholestane- $3 \alpha, 7 \alpha, 12 \alpha, 25$-tetrol accumulates and undergoes further hydroxylation reactions (e.g. at C-22 and C-23).

It seems most unlikely that our patient has 27-hydroxylase deficiency (i.e. a variant of CTX). His major problem has been cholestatic liver disease of neonatal onset; cholestatic liver disease has never been described in CTX. Furthermore, in CTX, the major urinary bile alcohols are $\mathrm{C} 22, \mathrm{C} 25$ pentols and C23,C25 pentols whereas in our patient the $\mathrm{C} 24(S), \mathrm{C} 25$ pentol predominated. In retrospect, it would have been useful to measure plasma 26-hydroxycholesterol in our patient. Plasma 26-hydroxysterol is low in patients with CTX and is a direct indication of reduced activity of the sterol 27-hydroxylase (which hydroxylates cholesterol as well as intermediates such as $5 \beta$-cholestane- $3 \alpha, 7 \alpha, 12 \alpha$-triol).

It also seems unlikely that our patient has a deficiency of an enzyme in the 27 -hydroxylase pathway distal to $5 \beta$-cholestane$3 \alpha, 7 \alpha, 12 \alpha, 27$-tetrol. This would be expected to produce substantial accumulation of the tetrol or of $\mathrm{C}_{27}$ bile acids; these would have been detected by our analyses and were not present.

Thus the available evidence supports the thesis that our patient has a deficiency in the side chain cleavage step(s) of the 25-hydroxylase pathway. If so, the severe deficiency of primary bile acids documented in the first year of life suggests that either the 25-hydroxylase pathway is the major route for bile acid synthesis at this age or accumulation of bile alcohols blocks reactions in the 27-hydroxylase pathway. So far, the evidence has tended to indicate that the 25-hydroxylase pathway is relatively unimportant in man; however, this evidence needs to be critically examined. Important studies by Duane $e t$ al. (23) used cholesterol labeled with ${ }^{14} \mathrm{C}$ in the C-26 (C-27) position. Conversion to bile acids via the 27-hydroxylase pathway should yield $\left[{ }^{14} \mathrm{C}\right.$ propionyl-CoA and hence ${ }^{14} \mathrm{CO}_{2}$, whereas oxidation of the $\left[{ }^{14} \mathrm{C}\right]$ cholesterol by the 25 hydroxylase pathway should yield $\left[{ }^{14} \mathrm{C}\right]$ acetone. Very little labeled acetone was formed, suggesting that the 25hydroxylation pathway accounts for $<5 \%$ of bile acid synthesis. These conclusions depend upon the assumption that orally administered cholesterol enters a single pool that supplies all biosynthetic routes to bile acids. This assumption may not be valid (24). More importantly, similar studies have not been performed in infants. 
Kase et al. (25) have used an experiment of nature to try to delineate the relative contributions of the two pathways of side chain oxidation in infancy. This relied upon the fact that the 27 -hydroxylase pathway involves the $\beta$-oxidation of $\mathrm{C}_{27}$ bile acids in the peroxisomes. Patients with Zellweger syndrome lack peroxisomes, and for this reason the 27-hydroxylase pathway is blocked. Kase et al. (25) found that the rate of conversion of $5 \beta$-cholestane- $3 \alpha, 7 \alpha, 12 \alpha$-triol to cholic acid in an infant with Zellweger syndrome was $15-20 \%$ of that seen in normal subjects, and the overall synthesis rate of cholic acid was $10 \%$ of normal. They concluded that when the 27 hydroxylase pathway is blocked cholic acid synthesis is severcly inhibited, indicating that the 27 -hydroxylase pathway is the major pathway for cholic acid synthesis. However, it should be remembered that patients with Zellweger syndrome have a plethora of biochemical abnormalities that stem from their inability to assemble normal peroxisomes. For example they lack sterol-carrier protein-2 (nonspecific lipid transport protein), which is important for the activity of cholesterol $7 \alpha$-hydroxylase-the ratc-limiting step in bile acid synthesis $(26,27)$. Furthermore, most patients (including the infant studied by Kase et al.) have elevated transaminases, and most develop hepatic fibrosis or cirrhosis. It is well known that cholic acid synthesis rates are easily depressed by acute or chronic hepatocyte damage (28); this is not due to a problem in the peroxisomes because $\mathrm{C}_{27}$ bile acids do not accumulate. If, instead of looking at patients with disorders of peroxisome biogenesis, we look at patients with defects of single enzymes in the peroxisomal $\beta$-oxidation pathway (e.g. trifunctional protcin deficiency, peroxisomal thiolase deficiency) a different pattern emerges $(2,14)$. These patients accumulate $\mathrm{C}_{27}$ bilc acids (and very long chain fatty acids), but they do not have some of the other biochemical abnormalities of the biogenesis defects. Standard liver function tests and liver histology are virtually normal. Cholic and chenodeoxycholic acid are readily detectable in duodenal bile and plasma and there is no cholestasis. This suggests that it is possible to have a defect of the 27-hydroxylase pathway without severely disrupted bile acid synthesis. By contrast the patient described in this report, who probably has a defect of the 25-hydroxylase pathway, has evidence of markedly reduced bile acid synthesis; this would be compatible with the 25-hydroxylase pathway being the major pathway for side chain oxidation in infancy.

The cause of liver damage in inborn errors of bile acid synthesis is uncertain. Two mechanisms that have been considered are l) loss of the bile acid-dependent component of bilc flow leading to hepatic retention of toxic compounds normally excreted in bile and 2) direct toxicity of intermediates in bile acid synthesis or compounds derived from them. Oral bile acid therapy has been proposed on the basis that it will both fucl bile flow and reducc synthesis of toxic intermediates (by inhibition of cholesterol $7 \alpha$-hydroxylase). However, treatment with chenodeoxycholic acid requires cxtreme caution because an excess of this hydrophobic bile acid can lead to deterioration in liver function (e.g. rises in transaminases when chenodeoxycholic acid is used for gallstone dissolution). In three patients with $3 \beta$-hydroxy- $\Delta^{5}-\mathrm{C}_{27}$-steroid dehydrogenase deficiency, we have observed an improvement in LFT within 1 mo of starting chenodeoxycholic acid therapy. In a fourth patient with very severe cholestasis and hepatocyte damage, the bilirubin and AST rose when treatment with chenodeoxycholic acid was instituted and improved slowly only when the regimen was changed to a combination of cholic acid and chenodeoxycholic acid (2). The patient described in this study also had severe cholestasis and hepatocyte damage. When chenodeoxycholic acid treatment was commenced, there appeared to be an initial exacerbation of cholestasis, but when treatment with chenodeoxycholic and cholic acids was recommenced, there was a steady improvement with normalization of LFT in 4 mo. Biopsies covering 9 mo of treatment showed a reduction in the amount of hepatocellular necrosis and portal inflammation but a progression to cirrhosis despite treatment. Clinically the patient is extremely well at the age of $3 \frac{1}{2}$ y-a favorable outcome compared with that of his affected sibling who died at the age of $13 \mathrm{mo}$.

Acknowledgment. The authors thank Asprey PLC (London, $\mathrm{UK}$ ) for the donation of GC-MS cquipment.

\section{REFERENCES}

1. Björkhem I 1985 Mechanism of bile acid biosynthesis in mammalian liver. In Daniclsson H, Sjövall J (eds) Sterols and Bile Acids: Ncw Comprehensive Biochemistry, Vol 12. Elscvicr, Amsterdam, pp 231-278

2. Clayton PT 1991 Inborn errors of bile acid metabolism. J Inherit Metab Dis 14:478-496

3. Clayton PT, Lconard JV Lawson AM, Setchell KDR, Andersson S, Egestad B Sjövall J 1987 Familial giant cell hepatitis associated with synthesis of $3 \beta, 7 \alpha$-dihydroxy- and $3 \beta, 7 \alpha, 12 \alpha$-trihydroxy-5-cholenoic acids. J Clin Invest 79:1031-1038

4. Buchmann MS, Kvittingen EA, Nazer H, Gunasckaran T, Clayton PT, Sjövall J, Björkhem I 1990 Lack of $3 \beta$-hydroxy- $\Delta^{5}-\mathrm{C}_{27}$-sleroid dehydrogenasc/isomerase in fibroblasts from a child with urinary excretion of $3 \beta$-hydroxy- $\Delta^{5}$-bile acids: a new inborn crror of metabolism. J Clin Invest 86:2034-2037

5. Ichimiya II, Nazer H, Gunasckaran T, Chayton P, Sjövall J 1990 Treatment of chronic liver disease caused by $3 \beta$-hydroxy- $\Delta^{5}-\mathrm{C} 27$-steroid dehydrogenase deficiency with chenodeoxycholic acid. Arch Dis Child 65:1121-1124

6. Ichimiya H, Egestad B, Nazer H, Baginski ES, Clayton PT, Sjövall J 1991 Bilc acids and bile alcohols in a child with hepatic $3 \beta$-hydroxy- $\Delta^{5}-C_{27}$-stcroid dehydrogenase deficiency: cffects of chenodeoxycholic acid treatment. J Lipid Res 32:829-84 I

7. Horslen SP, Lawson AM, Malone M, Clayton PT $19923 \beta$-Hydroxy- $\Delta^{5}-C_{27}$-steroid dehydrogenase deficiency; effect of chenodecoxycholic acid therapy on liver histology. I Inherit Metab Dis 15:384-386

8. Björkhem 1, Skrede S 1989 Familial diseases with storage of sterols other than cholesterol: cerebrotendinous xanthomatosis and phytostcrolaemia. In: Scriver CR, Beaudet AL, SIy WS, Valle D (eds) The Metabolic Basis of Inherited Disease, 6th Ed. McGraw Hill, New York, pp 1283-1302

9. Björkhem I 1992 Mechanism of degradation of the steroid side-chain in the formation of bile acids. J Lipid Res 33:455-471

10. Shefer S, Cheng FW, Dayal B, Hauser S, Tint GS, Salen G, Mosbach EH 1976 A 25-hydroxylation pathway of cholic acid biosynthesis in man and rat. J Clin Invest 57:897-903

11. Clayton PT, Mulker DPR 1980 A simplified gas-liquid chromatographic method for the estimation of non-sulphated plasma bile acids. Clin Chim Acta 105:401-405

12. Clayton PT 1983 The validation and application of an assay for the measurement of bile acids in the plasma of infants and children. MD thesis, University of Cambridge, Cambridge, UK

13. Clayton PT, Lake BD, Hall NA, Shortland DB, Carruthers RA, Lawson AM 1987 Plasma bile acids in pcroxisomal dysfunction syndromes: analysis by capillary gas chromatography-mass spectrometry. Eur J Pediatr 146:166-173

14. Clayton PT, Patel E, Lawson AM, Carruthers RA, Collins J 1990 Bile acid profiles in peroxisomal 3-oxoacyl-CoA thiolase deficiency. J Clin Invest 85:1267-1273

15. Lawson AM, Madigan MJ, Shortland DB, Clayton PT 1986. Rapid diagnosis of Zcllweger syndrome and infantile Refsum's disease by fast atom bombardment-mass spectrometry of urine bile salts. Clin Chim Acta 161:221-231

16. Cronholm T, Johansson G 1970 Oxidation of $5 \beta$-cholestane- $3 \alpha, 7 \alpha, 12 \alpha$-triol by rat liver microsomes. Eur J Biochem 16:373-381

17. Shefer S, Dayal B, Tint GS, Salen G, Mosbach EH 1975 Identification of pentahydroxy bile alcohols in cercbrotendinous xanthomatosis (CTX). Characterisation of $5 \beta$-cholestane- $3 \alpha, 7 \alpha, 12 \alpha, 24,25$-pentol and $5 \beta$-cholestane- $3 \alpha, 7 \alpha, 12 \alpha, 23,25$-pcntol. J Lipid Res 16:280-286 
18. Tint GS, Dayal B, Batta AK, Shefer S, Cheng FW, Salen G, Mosbach EH 1978 Gas-liquid chromatography-mass spectrometry of trimethylsilyl ethers of bile alcohols. J Lipid Res 19:956-966

19. Aringer L, Nordström I 1981 Chromatographic behaviour and mass spectrometric fragmentation of dioxygenated $\mathrm{C}_{27^{-}}, \mathrm{C}_{28^{-}}, \mathrm{C}_{29^{-}}$-steroids. Biomed Mass Spectrom 8:183:203

20. Sjövall J, Lawson AM, Setchell KDR 1985 Mass spectrometry of bilc acids. Methods Enzymol 111:63-113

21. Lawwson AM, Setchell KDR 1988 Mass spectrometry of bilc acids. In Setchell KDR, Kritchevsky D, Nair PP (eds) The Bile Acids, Vol 4. Plenum, New York, pp 167-267

22. Wolthers BG, Volmer M, van der Molen J, Koopman BJ, De Jager AEJ, Waterreus RJ 1983 Diagnosis of ccrebrotendinous xanthomatosis (CTX) and effect of chenodeoxycholic acid therapy by analysis of urine using capillary gas chromatography. Clin Chim Acta 131:53-65

23. Duane WC, Pooler PA, Hamilton JN 1988 Bilc acid synthesis in man. In vivo activity of the 25-hydroxylation pathway. J Clin Invest 82:82-85
24. Spady DK, Dietschy JM 1986 Hepatic bile acid synthesis: studics on regulation using rats whose total body pool of cholesterol is uniformly labelled with ${ }^{3} \mathrm{H}$. In: Paumgartner G, Stichl A, Gerok W (eds) Bile Acids and the Liver. Falk Symposium 45. MTP Press (Kluwer), Lancaster, UK, pp 15-24

25. Kase BF, Björkhem I, Haga P, Pedersen JI 1985 Defective peroxisomal cleavage of the $\mathrm{C}_{27}$-steroid side chain in the cerebro-hepato-renal syndrome of Zellweger. J Clin Invest $75: 427-435$

26. Suzuki Y, Yamaguchi S, Orii T, Tsuneoka M, Tashiro Y 1990 Nonspecific lipid transfer protein (sterol carrier protein-2) defective in patients with deficient peroxisomes. Cell Struct Funct 15:301-308

27. Scallen TJ, Vahouny GV 1985 Participation of sterol carrier proteins in cholesterol biosynthesis, utilisation and intracellular transfer. In: Danielsson H, Sjövall (eds) Sterols and Bile Acids: New Comprchensive Biochemistry, Vol 12. Elsevier, Amsterdam, pp 73-93

28. Vlahcevic ZR, Prugh MF, Gregory DH, Swell L 1977 Disturbances of bile acid metabolism in parenchymal liver cell discase. Clin Gastrocnterol 6:25-44 